by the molars of the numerous types of ungulates peculiar to the Tertiary formations of South America, Dr. Ameghino has almost a superfluity of material upon which to work. So vast, indeed, is his subject, that it would be impossible, within the limits of our space, to follow him in his survey from one type to another, or, indeed, to discuss his general conclusions, and I shall therefore confine myself to directing the attention of my readers to certain points of special interest in the author's work.

In the first place, it may be noted that Dr. Ameghino reiterates his opinion as to the falsity of the tritubercular theory of molar development, tritubercular molars, instead of being the primitive type, having been derived, on his view, from those with four or six cusps. Whether this opinion is in any way biased by the author's contention that the earlier Patagonian mammals are of Cretaceous age may be worth consideration.

Of greater importance is the support given by Dr. Ameghino to the view that the molar formula of the placental and marsupial carnivores is numerically identical, that is to say, that there are three true molars in both (when the full series is developed) instead of three in the one and four in the other. $\mathrm{He}$ consequently regards the replacing marsupial premolar as the third instead of the fourth, and the tooth behind it as a persistent milk-molar. The numerical identity

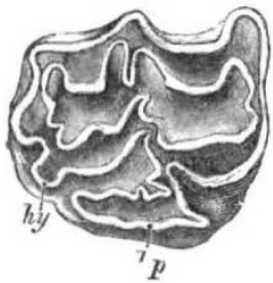

FIG. r.-Right upper molar of horse. $p$, antero-internal pillar; hy, pos tero-internal pillar.

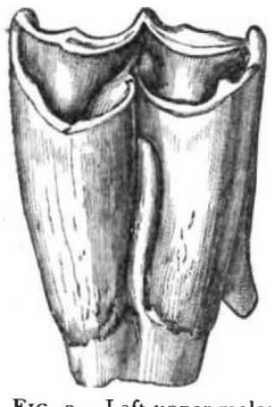

FIG. 2-Left upper molar of Nilgai to show accessory pillar between the two main inner crescents. of the marsupial and placental series was urged long ago by Prof. Gaudry, and this view was more fully developed a few years since by the present writer, when evidence in favour of the above-mentioned homology of the marsupial replacing tooth and the one behind it was likewise adduced. Although it has subsequently received the assent of Dr. Wortman, this view has not, however, yet been accepted by zoologists generally. It may be added that it is a question on which only those with a considerable amount of palæontological knowledge are competent to form an opinion.

Another point of great interest referred to in Dr. Ameghino's memoir is the alleged occurrence in Nesodon and certain other Patagonian Tertiary mammals of three distinct dentitions. Since the existence of this remarkable phenomenon is stated to have been accepted by Dr. Scott, it may apparently be taken as fully authentic. The "pre-lacteal" cheek-dentition, according to the figure given, consists of three very small teeth, differing somewhat in form from their successors of the milk-series. Dr. Ameghino, whose view is almost certainly in this instance influenced by his opinion as to the age of the Patagonian mammals, regards the "pre-lacteal" dentition as a direct inheritance from reptilian ancestors. In view, however, of the specialised characters of Nesodon and its allies, and the absence of a functional "pre-lacteal" series in any other mammals, it would seem much more probable that it is a superadded feature.

The last point to which we have space to allude relates to the homology of two of the cusps in the equine molar. To render this point clear, two figures have been introduced into this notice.

Since the date of publication of the first part of Gaudry's "Enchainements," the antero-pillar of the equine molar ( $p$ in Fig. I) has been almost universally regarded as one of the primitive constituents of the tooth, corresponding to the inner extremity of the anterior transverse ridge (protocone) of the rhinoceros or anchitherium molar. From comparison with a large number of extinct forms, Dr. Ameghino comes, however, to the conclusion that this antero-internal pillar (which is detached in Hipparion but joined to the body of the tooth in Equus) is really a superadded element, derived from the cingulum, and corresponding to the "accessory pillar" of the molars of many ruminants (Fig. 2). Consequently, the protocone will be represented by a part of the anterior inner crescent of the horse's molar. Apparently Dr. Ameghino has made out a very strong, if not a conclusive, case for the new interpretation; I may add that the same opinion was independently arrived at and published by Dr. Forsyth-Major so long ago as 1873 , but has been generally neglected in favour of the Gaudrian theory.

Without in any way endorsing all his views, it may be confidently stated that in this memoir Dr. Ameghino has made a very important contribution to mammalian odontology.

R. L.

\section{DR. ISAAC ROBERTS, F.R.S.}

THERE is one class of scientific amateurs which seems to be the peculiar product of English society. Dealing with astronomy alone, and confining nur attention to those who have passed away, we have such men as Lassell, Barclay, De La Rue, \&c., all of whom, after amassing a considerable fortune in commercial pursuits, have devoted the evening of their lives to furthering the interests of their favourite science. The latest example of this earnest attachment to this particular branch of science was Dr. Isaac Roberts, whose death we record with profound regret. It is possible that he may be nearly the last of a distinguished series, for it is not unlikely that, as science tends to specialise in particular directions, such instances will become less and less frequent. The wealthy amateur, it may be, will continue to provide the means for others, but the requirements for the production of valuable work tend to become more and more severe, and the actual prosecution will soon be reserved to those who have been able to give up their whole life to special study. But Dr. Roberts was fortunate in finding a subject at which he could work with effect personally, and his own exertions were rewarded with valuable results.

For some years Dr. Roberts seems to have wavered between geology and astronomy as a congenial pursuit in his leisure hours. But possibly it was the application of some form of mechanical inquiry that attracted him in either direction. Among his early papers are the results of investigations affecting the circulation of underground water and the filtering and hygroscopic properties of Triassic sandstone. In studying the movements of underground waters, of which the observations were carried on with great regularity, he employed mechanical contrivances which he designed himself. Similarly, in practical questions such as the determination of the pressure of grain on the walls of lofty warehouses, when stored to great height, the mechanical side of the question seems to

No. I8I3, voL. 70] 
have had the greatest attraction for him. Finally, when he settled down to the continuous study of astronomy and procured a powerful reflector suitable for his purpose, he introduced many small conveniences to assist the work, which no doubt contributed in a large measure to his ultimate success; for at the time he began his work astronomers had not recognised with the keenness they do now the necessity of controlled driving clocks to equatorials, and other happy suggestions for lightening the labour or the irksomeness of prolonged exposure in photographic work. This was the direction in which Dr. Roberts chose to work, and in which he earned a well merited reputation. It may be said of his early photographs that they were a revelation, and they are still worthy of profound study, though others working with more powerful instruments, and guided, it may be, by his early experience, have equalled and possibly surpassed them in the amount of detail shown. Two handsome volumes containing photographs of nebulæ and star clusters, which Dr. Roberts published at his own expense and widely distributed, speak to his industry and liberality, and his mechanical genius found another outlet by constructing a machine for the ready copying or transference of the positions of the stars photographed, to copper plates, from which they could be readily printed. How far this device has been used is uncertain: probably mechanical photographic processes have supplanted it.

Another feature in Dr. Roberts's methods which was eminently practical and worthy of imitation was the care he displayed in selecting a site for his observatory. His desire was to secure a good observing atmosphere and the greatest freedom from clouds, and many and minute were his inquiries, both at home and abroad, before he settled on Crowborough Hill, where his observatory was finally situated. Even shortly before his death he visited Las Palmas for the purpose of making some observations which required good observing conditions, and it will be to the regret of many friends that his activity and his energy are lost to us while he was still eager and capable of pursuing his favourite study.

The deceased astronomer, who had been elected a fellow of the Royal Society and many other learned bodies, was in his seventy-fifth year. He was twice married, on the second occasion to Miss Dorothea Klumpke, whose name and reputation are known throughout Europe, and to whom the deepest sympathy will be tendered.

\section{NOTES.}

WE regret to have to record the death, at the age of eighty-two, of Sir John Simon, K.C.B., F.R.S., which took place on Saturday last.

THe death is announced of Prof. Trasbot, formerly director of the Alfort School, at the age of seventy-two years. He had been a member of the Paris Academy of Medicine since I886, and was the author of many works relating to pathology, epidemic diseases, and sanitary administration.

THE death is announced also of Dr. J. Bell Hatcher, curator of vertebrate zoology at the Carnegie Museum, Pittsburg, at the age of forty-six years.

THE Berlin correspondent of the Lancet states that Prof. Koch will vacate his position as chief of the Royal Institution for Infectious Diseases on October $\mathbf{I}$, in order that he may have more time for scientific research. He will, however, continue to be connected with the institution, and, by special order of the Government, will have on the premises a laboratory furnished at the public expense, and the clinical material of the institution will be placed at his disposal. We learn also from the same source that Prof. Koch is to succeed Prof. Virchow in the membership of the Royal Academy, Berlin, and that his successor as chief of the Institution for Infectious Diseases will be Prof. Gaffky, now of the University of Giessen. Prof. Gaffky's acceptance of Prof. Koch's chair in the University of Berlin was announced in our issue of July $\mathrm{I}_{4}$.

IT is announced in Science that Mr. H. C. Russell, Government Astronomer of New South Wales, is to retire at the end of the present year, after forty-six years' service.

THE seventy-second annual meeting of the British Medical Association was opened at Oxford on Tuesday last, when the president, Dr. Collier, delivered his address. In the evening a reception was held in the Sheldonian Theatre, and the Middlemore prize for the best original work on ophthalmology brought out during the past three years was awarded to Mr. J. Herbert Parsons.

THE Lord Provost of Glasgow opened on Thursday last the health exhibition which has been organised in connection with the twenty-ninth autumn congress of the Sanitary Institute now in session at Glasgow. The exhibition is divided into colonial, municipal, and educational sections, and among the exhibits are a model hospital and a model one-house dwelling.

THE congress of the Royal Institute of Public Health at Folkestone was opened on Thursday last and closed on Tuesday.

AN intercolonial agricultural conference was opened in Pretoria on Monday last, and the delegates will discuss, among other subjects, the formation of a Central South African Agricultural Union, African coast fever, the native question, irrigation, and fruit and cotton growing.

THE sixth centenary of the birth of Petrarch opened at Arezzo on July 20. The Count of Turin represented the King of Italy, and Signor Orlendo, Minister for Public Instruction, represented the Italian Government. An artistic tablet was unveiled at the house in the Via dell' Orto in which Petrarch was born, and later there was a memorial ceremony in the Politeama Aretino. The festivities lasted until July 25 .

THE new hall of the Royal Horticultural Society in Vincent Square, Westminster, was opened by His Majesty the King on Friday last. The building, which includes a library, offices, council chambers, and a lecture room, in addition to the large hall in which the society will hold its fortnightly exhibitions, has been built to celebrate the centenary of the society. In the address which Sir Trevor Lawrence read to the King and Queen the work of the Royal Horticultural Society was reviewed, and in regard to the efforts of the collectors sent out by the society in the nineteenth century, it was said, in the words of $\mathrm{Mr}$. Andrew Murray, that "the results have affected the appearance of all England. Nowhere can a day's ride now be taken where the landscape is not beautified by some of the introductions of the Royal Horticultural Society." Perhaps nothing irdicates more clearly the way in which the society has promoted the science and art of horticulture than the fact that whereas there were one thousand three hundred fellows in 1887 , there are now eight thousand, one hundred and fifty. Baron Sir Henry Schroeder presented the report of the building and appeal committees, in which it was stated that twenty-six thousand pounds had been subscribed towards the cost of the hall, which will amount in the end to forty

No. I 8 I 3 , vOL. 70] 